\title{
PENGARUH EKSPEKTASI PELANGGAN, KUALITAS PRODUK DAN KEPUASAN PELANGGAN TERHADAP LOYALITAS PELANGGAN INTERNET TELKOMSEL DI BANDA ACEH
}

\author{
Yohandes Rabiqy \\ Universitas Teuku Umar, Meulaboh \\ Email : rabiqy85@gmail.com
}

\begin{abstract}
This research aims to examine the factors that influence the level of internet customer loyalty Telkomsel in Banda Aceh. The population of this research is the customer who use or are subscrib to Internet service Unlimited Telkomsel Flash, and a minimum for six months subscription. Multiple linear regression analysis is used to determine the effect of variable customer expectations, product quality, and customer satisfaction is hypothesized to effect on customer loyalty. The results of multiple linear regression analysis showed that the dominant factor that affect the customer loyalty is the variable quality of the product, followed by a variable customer expectations, and the least effect on customer loyalty is customer satisfaction variables. The variables of this research are quite good in explaining customer loyalty. The advice from the author to the company is that companies have to create products that are superior in quality, and always maintain the quality of the product to constantly innovate on products tailored to the desires of customers to the product. Furthermore, the company have to pay attention to the complaints of customers by minimizing customer complaints.
\end{abstract}

Keywords: Expectations, product quality, customer satisfaction, customer loyalty

\section{PENDAHULUAN}

Pertumbuhan akses internet saat ini sangat pesat. Diawali dengan masuknya internet sekitar tahun 1994, saat ini pemakai internet di indonesia sudah mencapai 53 juta, meningkat $1300 \%$ dari hanya sekitar 4 juta di tahun 2000. Dari data pertumbuhan tersebut menunjukkan bahwa pertumbuhan pengguna internet di indonesia berkembang sangat pesat. Karena belakangan ini internet dirasakan memiliki berbagai manfaat berarti bagi masyarakat, terutama bagi beberapa golongan yang sangat memperhatikan perkembangan teknologi.

Secara umum manfaat yang dapat diperoleh apabila seseorang mempunyai akses ke internet adalah memperoleh informasi yang luas tanpa batas secara individu, sosial, maupun informasi bisnis/pekerja pun dapat diperoleh melalui akses internet. Akses informasi internet tidak mengenal batas geografis, ras, suku, budaya, negara, maupun kelas ekonomi, atau faktor-faktor lain yang 
biasanya dapat menghambat pertukaran pikiran. Dari aktifitas tanpa batas ini internet mampu menciptakan suatu komunitas-komunitas unik seperti kaskus, facebook, twitter. Dan tidak menutup kemungkinan melalui komunitas dalam internet tersebut dapat terjalin kerjasama bisnis. Karena banyaknya manfaat tersebut, maka dewasa ini pengguna internet semakin meningkat jumlahnya seiring dengan banyaknya kemudahan-kemudahan yang diperoleh dalam penggunaan internet.

Karena ada kebutuhan dan permintaan yang terus meningkat setiap tahunnya, terutama untuk jasa internet. Permintaan akan jasa internet ini semakin marak dan melonjak dari seluruh penjuru nusantara. Jasa internet ini dirasakan sebagai bisnis yang potensial dan menghasilkan margin yang menguntungkan bagi perusahaan. Melihat potensi tersebut banyak perusahaan provider telekomunikasi selular yang mencoba peruntungannya dan terjun ke dalam bisnis jasa internet. Terdapat beberapa raksasa provider selular di tanah air yang merambah bisnis internet, antara lain Telkomsel dengan jagoan produknya Flash unlimited, Flash prepaid . Indosat dengan jagoan produknya Broom dan IM2. Telkom dengan andalannya Speedy dan Telkom-Net instant, dll. Kesemua provider tersebut berusaha meraih pasar sebesar-besanya dengan berbagai strategi yang diterapkan. Perang tekhnologi antar provider pun tidak dapat dihindarkan, karena semua operator tersebut berusaha memberikan layanan yang terbaik bagi setiap pelanggannya dan menyediakan nilai lebih dibanding provider lainnya. Setiap provider berusaha memberikan layanan yang terbaik kepada setiap pelanggannya, berusaha mengaplikasikan tekhnologi yang tercanggih dan mutakhir dalam setiap layanannya (4G, HSDPA, EDGE, 3G, GPRS, MMS), menciptakan suatu akses internet yang cepat, memperluas jangkauan jaringan (coverage area) sehingga akses internet dapat dilakukan disetiap wilayah atau daerah, kemudian menawarkan tarif yang semurah mungkin dan bersaing dengan kompetitornya.

Telkomsel Flash Unlimited adalah produk PT. Telkomsel dengan layanan akses internet nirkable (wireless) kecepatan tinggi melalui laptop,PC (Personal Computer) yang dapat diakses melalui modem datacard, ponsel, gadget maupun router. Layanan ini disediakan oleh Telkomsel untuk seluruh pelanggannya pengguna KartuHALO. Telkomsel Flash menawarkan suatu pengalaman baru dalam melakukan koneksi jaringan internet dengan kecepatan tinggi (hingga 3,2 Mbps) dan lokasi akses yang dapat dilakukan dimana saja dalam jangkauan jaringan HSUPA, HSDPA, 3G, EDGE ataupun GPRS. Layanan akses internet milik Telkomsel ini pertama kali diluncurkan pada 06 April 2007, di Jakarta.

PT. Telkomsel merupakan salah satu perusahaan provider di Indonesia yang masih menjadi market leader dan memiliki market share terbesar dalam industri seluler GSM (Global System Mobile) pra bayar. Dengan diciptakannya suatu layanan internet Flash unlimited dan Flash prepaid, PT. 
Telkomsel mencoba peruntungan bisnis baru dalam bidang internet. Sebagai pendahulu BTS (Base Transceiver Station) milik PT. Telkomsel lebih banyak tersebar ke beberapa penjuru nusantara, bahkan untuk kenyamanan akses internet konsumennya PT. Telkomsel tidak segan-segan untuk menambah kuantitas terabit per bulannya dan kapasitas jaringan data Telkomsel telah dipersiapkan mencapai 6.000 terabit, tekhnologi fiture yang diberikan juga cukup canggih dan up to date dengan adanya kerjasama bundling USB modem dengan Telkomsel. Semestinya hal ini menjadi daya tarik tersendiri bagi para pelanggannya, namun hal tersebut tidak cukup untuk tetap mempertahankan diri sebagai Market leader.

Perusahaan dituntut mampu menawarkan barang atau jasa dengan mutu atau pelayanan yang diberikan pada konsumen dari waktu ke waktu, karena konsumen yang semakin pandai dan terdidik, menyebabkan keinginan dan kebutuhannya berubah sangat cepat. Perusahaan sudah semestinya berorientasi pada pelanggan, agar dapat memenangkan persaingan. Dengan memberikan kepuasan pada pelanggan akan membangun kesetiaan pelanggan dan akhirnya dapat menciptakan hubungan yang erat antara pelanggan dan perusahaan.

Fenomena bisnis yang terjadi saat ini adalah perang tarif antar provider layanan internet yang berlangsung gencar dan sengit. Perang tarif ini dikomunikasikan secara besar-besaran dan terangterangan di berbagai media masa baik cetak maupun elektronik. Bentuk penawaran ini mempengaruhi pola pemikiran dari para konsumen, terutama mengenai harga yang sangat mempengaruhi pola pikir konsumen.

Setiap provider berlomba-lomba memberikan fasilitas dan penawaran terbaik demi kepuasan kepada para pelanggannya. Kepuasan pelanggan sangat tergantung pada kinerja dan berpikir positifnya pelanggan. Kepuasan adalah tingkat perasaan seseorang setelah membandingkan kinerja atau outcame yang dirasakan dengan harapan-harapan terhadap produk tersebut (Philip Kotler, 2007). Tingkat kepuasan pelanggan merupakan perbedaan daya guna yang dirasakan konsumen (perceived performance atau perceived outcame) dan ekspektasi yang ada.

Bagi perusahaan yang berorientasi kepada pelanggan (customer oriented), kepuasan pelanggan menjadi sasaran kiat pemasaran. Pelanggan yang dapat tingkat kepuasan tinggi akan memberi ikatan pada merek produk, bukan hanya preferensi nasional dan akhirnya semua ini membangun loyalitas pelanggan.

Bagi perusahaan, konsumen yang loyal sangat besar artinya selain menggambarkan besarnya profitabilitas yang diperoleh konsumen yang loyal juga dapat menunjukan citra atau image perusahaan 
di mata public. Bahkan menurut Graham, customers lebih penting dari orders. Membangun loyalitas pelanggan dan terciptanya customers relationship adalah hal terbaik yang dimiliki perusahaan (Lena Ellitan, 2009). Pelanggan yang setia dapat menjadi partner dalam mengembangkan produk baru, karena mereka mempertahankan dan membela bahkan menggunakan pelayanan perusahaan yang ada.

Dengan adanya deregulasi kebijakan tarif yang ditetapkan setiap operator, hal tersebut otomatis akan mempengaruhi kesetiaan jumlah pelanggan setiap operatornya. Hal ini merupakan persoalan mendasar bagi pihak perusahaan. Syarat yang harus dipenuhi oleh suatu perusahan agar sukses dalam persaingan adalah berusaha mencapai tujuan untuk menciptakan dan mempertahankan pelanggan (Fandy Tjiptono, 2001). Dengan memahami perilaku konsumen, pihak perusahaan dapat mengetahui faktor-faktor apa saja yang dipertimbangkan pelanggan dalam memilih layanan internet yang ditawarkan berbagai provider telekomunikasi, sehingga dapat menetapkan strategi sesuai dengan keinginan pelanggan.

Variabel ekspektasi pelanggan diyakini memunyai peranan yang besar dalam menentukan kualitas produk (barang atau jasa) dan kepuasan pelanggan. Dalam mengevaluasinya, pelanggan akan menggunakan harapannya sebagai standard atau acuan pelanggan dalam memilih suatu produk (barang maupun jasa).

Variabel kualitas produk adalah variabel pembanding antara produk yang diharapkan dengan produk yang diterima konsumen. Variabel kepuasan adalah variabel yang menjelaskan respon konsumen terhadap evaluasi diskrepansi atau ketidaksesuaian yang dirasakan antara ekspektasi sebelumnya dengan kinerja sesungguhnya dari produk yang telah dikonsumsi (Tse dan Wilton dalam Kadampully dan Suhartanto, 2000).

Pada penelitian yang akan dilakukan saat ini akan meneliti loyalitas konsumen pengguna layanan internet Telkomsel (Flash Unlimited). Adapun beberapa variabel yang diambil adalah ekspektasi pelanggan, kualitas produk, kepuasan pelanggan dan berpengruh terhadap loyalitas. Judul yang diambil dalam penelitian ini adalah "Pengaruh Ekspektasi Pelanggan, Kualitas Produk, dan Kepuasan Pelanggan Terhadap Loyalitas Pelanggan Internet Telkomsel di Banda Aceh”

\section{PERUMUSAN MASALAH}

Dari latar belakang masalah yang telah diuraikan dapat dirumuskan permasalahan sebagai berikut: 
1. Berapa besar variabel ekspektasi pelanggan berpengaruh terhadap loyalitas pelanggan pengguna layanan internet Telkomsel?

2. Berapa besar variabel kualitas produk berpengaruh terhadap loyalitas pelanggan pengguna layanan internet Telkomsel?

3. Berapa besar variabel kepuasan pelanggan berpengaruh terhadap loyalitas pelanggan pengguna layanan internet Telkomsel ?

\section{TUJUAN PENELITIAN}

Sesuai dengan permasalahan yang telah dirumuskan, tujuan penelitian yang hendak dicapai adalah sebagai berikut:

1. Mengetahui besar pengaruh faktor ekspektasi pelanggan terhadap loyalitas konsumen

2. Mengetahui besar pengaruh faktor kualitas produk terhadap loyalitas konsumen.

3. Mengetahui besar pengaruh faktor kepuasan konsumen terhadap loyalitas konsumen.

\section{TINJAUAN PUSTAKA}

\section{Ekspektasi Pelanggan}

Ekspektasi atau harapan merupakan perkiraan atau keyakinan pelanggan tentang apa yang akan diterimanya. Pengertian ini didasarkan pada pandangan bahwa harapan merupakan standar prediksi yang dilakukan konsumen dalam melakukan pembelian.

Menurut Olson dan Dover (Zeithaml, 2003), harapan pelanggan merupakan keyakinan pelanggan sebelum mencoba atau membeli suatu produk, yang dijadikan standar atau acuan dalam menilai kinerja produk tersebut. Meskipun demikian, dalam beberapa hal belum tercapai kesepakatan, misalnya : sifat standar harapan yang spesifik, jumlah standar yang digunakan, maupun sumber harapan.

Menurut (Sri Mulyani, 2003) model konseptual mengenai harapan pelanggan terhadap jasa dipengaruhi oleh faktor-faktor sebagai berikut :

1. Enduring Service Intensifiers

2. Personal Need / Kebutuhan perorangan

3. Transitory Service Intensifiers

4. Perceived Service Alternatives

5. Self Percuived Service Role 
6. Situational Factors

7. Explicit Services Promises

8. Implicit Service Promises

9. Word - of - Mouth / Rekomendasi.

10. Past Experience / Pengalaman.

\section{Kualitas Produk}

Pada penelitian ini ditentukan empat indikator dari variabel Kualitas Produk menurut Fandy Tjiptono (2000), yaitu :

1. Kinerja (performance)

2. Keistimewaan tambahan (feature)

3. Kegunaan (Serviceability)

4. Kualitas yang dipersepsikan (perceived quality)

\section{Kepuasan Pelanggan}

Sesuai dengan yang dikatakan Philip Kotler dalam Saraswati (2008) yang menyatakan kunci untuk mempertahankan pelanggan adalah kepuasan pelanggan. Pelanggan yang puas akan :

1. Melakukan pembelian ulang

2. Mengatakan hal yang baik tentang perusahaan kepada orang lain (rekomendasi).

3. Kurang memperhatikan merek dan iklan produk pesaing.

4. Membeli produk lain dari perusahaan yang sama.

Menurut Fandy Tjiptono (2001) dalam Julita (2001) kepuasan pelanggan merupakan evaluasi purnabeli dimana alternatif dipilih sekurang-kurangnya memberi hasil yang sama atau melampaui harapan pelanggan, sedangkan ketidakpuasan pelanggan timbul ketika hasil (outcome) yang tidak sesuai dengan harapan.

\section{Loyalitas Pelanggan}

Menurut (Jacoby dan Olson, 1970) mengutarakan pengertian loyalitas pelanggan menekankan pada runtutan pembelian, proporsi pembelian, atau dapat juga probabilitas pembelian. Dalam lingkungan bisnis dimana persaingan berlangsung sangat keat sepeti saat ini, upaya memenangkan persaingan tidak hanya didasarkan pada mutu produk atau jasa yang tinggi, harga jual 
bersaing, tetapi juga upaya terpadu untuk memberikan kepuasan pada pelanggan dan memenuhi kebutuhan lebih baik sesuai dengan yang diharapkan pelanggan. Pelanggan yang setia bisa menjdi partner dalam mengembangkan produk baru. Mereka mempertahankan dan membela pelayanan perusahaan yang ada. Dalam penelitian ini ditentukan empat indikator variabel loyalitas pelanggan:

1. Pelanggan yang melakukan pembelian ulang secara teratur.

2. Pelanggan yang membeli produk yang lain di tempat yang sama.

3. Pelanggan yang mereferensikan kepada orang lain.

4. Pelanggan yang tidak dapat dipengaruhi pesaing untuk pindah.

\section{Kerangka Model Penelitian}

Sesuai dengan latar belakang penelitian dan penelitian sebelumnya yang telah dipaparkan, penelitian ini akan meneliti seberapa besar Pengaruh Ekspektasi Pelanggan, Kualitas Produk, dan Kepuasan Pelanggan Terhadap Loyalitas Pelanggan Layanan Internet Telkomsel di Banda Aceh. Kerangka pemikiran teoretis dapat dilihat dalam gambar berikut ini :

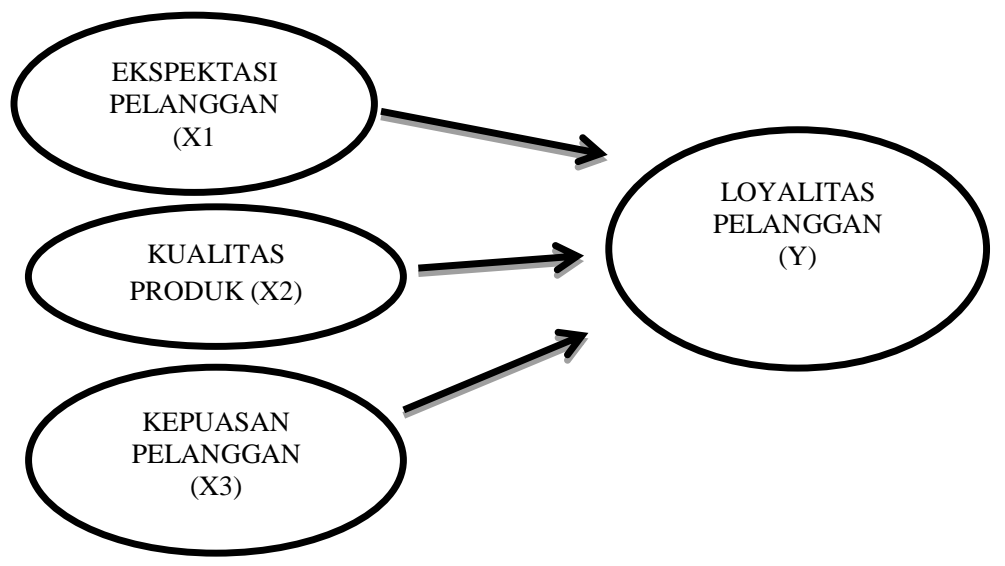

Sumber : dikembangkan untuk penelitian

Dari kerangka penelitian yang tertera diatas, variabel Harapan Pelanggan, Kualitas Produk, Kepuasan Konsumen mempengaruhi tingkat loyalitas pelanggan. 


\section{METODE PENELITIAN}

\section{Teknik Pengumpulan Data}

Metode pengambilan sample dengan menggunakan metode purposive sampling, yaitu pengambilan sample yang berdasarkan pertimbangan tertentu dan harus representative atau mewakili populasi yang akan diteliti.Untuk memperoleh data yang akurat dan relevan dengan penelitian ini, penulis melakukan serangkaian kegiatan pengumpulan data yang dimulai dengan kegiatan pengumpulan data melalui daftar pertanyaan yang disebarkan kepada konsumen yang menggunakan produk Telepon seluler di Kota Banda Aceh. Dalam hal ini diedarkan sebanyak 100 kuisioner. Selanjutnya Studi dokumentasi dilakukan dengan mengumpulkan dan mempelajari dokumen-dokumen serta data pendukung pelanggan Telkomsel Banda Aceh baik itu media cetak dan juga media elektronik

\section{Peralatan Analisis Data}

Dalam analisis ini dapat dilihat bagaimana variabel bebas, yaitu Ekspektasi pelanggan (X1), kualitas produk (X2), kepuasan pelanggan (X3) mempengaruhi (secara positif atau negatif) variabel terikat, yaitu loyalitas pelanggan (Y). Bentuk matematisnya adalah sebagai berikut

$$
\mathrm{Y}=\mathrm{b} 1 \mathrm{X} 1+\mathrm{b} 2 \mathrm{X} 2+\mathrm{b} 3 \mathrm{X} 3
$$

Dimana :

$\mathrm{Y}=$ loyalitas pelanggan

$\mathrm{b} 1-\mathrm{b} 3=$ koefisien regresi variabel X1-X3

$\mathrm{X} 1=$ ekspektasi pelanggan

$\mathrm{X} 2$ = kualitas produk

X3 = kepuasan pelanggan

\section{HASIL PENELITIAN DAN PEMBAHASAN}

Hasil penelitian ini mendapatkan hasil bahwa loyalitas pelanggan dapat dijelaskan oleh faktor harapan pelanggan, kualitas produk, kepuasan pelanggan. Diperoleh bahwa 68,8\% loyalitas konsumen dapat dijelaskan oleh ketiga variabel tersebut. Dari hasil pengujian variabel kualitas produk dapat disimpulkan bahwa variabel kualitas produk berpengaruh secara positif dan signifikan terhadap loyalitas pelanggan Telkomsel Flash Unlimited. Hal ini terbukti pada nilai t hitung $(4,888)$ lebih besar 
dari t tabel $(1,660)$ dengan nilai signifikansi 0,000 dengan menggunakan batas signifikansi 0,05 (Imam Ghozali, 2005). Pada variabel kualitas produk diperoleh rata-rata skor jawaban sebesar 67,45 yang berada dalam kategori sedang berdasarkan three box methode (Augusty Ferdinand, 2006). Pembuktian hipotesis 2 menunjukkan bahwa kualitas produk memiliki pengaruh yang signifikan terhadap loyalitas pelanggan. Dengan keunggulan kualitas produk yang baik, maka produk tersebut akan mengalahkan produk milik operator pesaing. Apabila suatu produk dapat memuaskan keinginan konsumen maka konsumen akanmemberikan penilaian positif terhadap poduk tersebut Dengan penilaian tersbut maka konsumen akan tetap berkeinginan untuk tetap menggunakan produk Telkomsel Flash Unlimited.

Dari hasil pengujian variabel harapan pelanggan dapat disimpulkan bahwa variabel harapan pelanggan berpengaruh secara positif dan signifikan terhadap loyalitas pelanggan Telkomsel Flash Unlimited. Hal ini terbukti pada nilai t hitung $(4,714)$ lebih besar dari t tabel $(1,660)$ dengan nilai signifikansi 0,000 82 dengan menggunakan batas signifikansi 0,05 (Imam Ghozali, 2005). Pada variabel harapan pelanggan diperoleh rata-rata skor jawaban sebesar 65,25 yang berada dalam kategori sedang berdasarkan three box methode (Augusty Ferdinand, 2006). Pembuktian hipotesis 1 diperoleh bahwa variabel harapan pelanggan menjadi standar prediksi yang dilakukan konsumen dalam melakukan pembelian, harapan pelanggan dijadikan standar atau acuan dalam menilai suatu kinerja produk, apabila harapan pelanggan dapat terpenuhi maka akan tercipta loyalitas dari konsumen tersebut. Dengan indikator personal need, explicit service promises, implicit service promises, past experience dapat menjadi suatu pertimbangan seorang konsumen untuk tetap menggunakan produk Telkomsel Flash.

Dari hasil pengujian variabel kepuasan pelanggan dapat disimpulkan bahwa variabel kepuasan pelanggan berpengaruh secara positif dan signifikan terhadap loyalitas pelanggan Telkomsel Flash Unlimited. Hal ini terbukti pada nilai t hitung $(3,954)$ lebih besar dari t tabel $(1,660)$ dengan nilai signifikansi 0,000 dengan menggunakan batas signifikansi 0,05 (Imam Ghozali, 2005). Pada variabel kepuasan pelanggan diperoleh rata-rata skor jawaban sebesar 66,90 yang berada dalam kategori sedang berdasarkan three box methode (Augusty Ferdinand, 2006). Pengujian hipotesis 3 menunjukkan adanya pengaruh yang signifikan antara variabel kepuasan pelanggan terhadap loyalitas pelanggan. Kepuasan pelanggan dapat menjadi dasar menuju terwujudnya konsumen yang loyal atau setia. Hasil penelitian ini sesuai dengan pernyataan Lena Elitan (1997), pelanggan yang mencapai tingkat kepuasan yang tinggi akan memiliki ikatan pada merek produk, bukan hanya preferensi rasional dan pada akhirnya akan membangun loyalitas pelanggan. Loyalitas konsumen dapat diprediksikan dari tingkat 
kepuasan konsumen yang diperoleh selama penggunaan akan suatu produk jasa, dengan indikator tidak ada keluhan pelanggan, perasaan puas akan keseluruhan produk, kesesuaian dengan expectasi, dan harapan yang terlampaui.

\section{KESIMPULAN DAN SARAN}

\section{Kesimpulan}

Dari hasil penelitian yang telah diuraikan, dapat ditarik kesimpulan sebagai berikut :

1. Hasil penelitian untuk hipotesis pertama diperoleh penjelasan bahwa variabel Ekspesitas Pelanggan memiliki pengaruh positif dan signifikan terhadap loyalitas pelanggan Internet Telkomsel di Banda Aceh.

2. Hasil penelitian terhadap hipotesis kedua diperoleh penjelasan bahwa variabel Kualitas Produk memiliki pengaruh positif dan signifikan terhadap loyalitas pelanggan Internet Telkomsel di Banda Aceh.

3. Sedangkan penelitian terhadap hipotesis ketiga dapat dijelaskan bahwa variabel Kepuasan Konsumen positif dan signifikan terhadap loyalitas pelanggan Internet Telkomsel di Banda Aceh.

\section{Saran}

1. PT.Telkomsel harus mempertahankan bahkan meningkatkan mutu produk yang memiliki kualitas unggul untuk disajikan kepada konsumen agar terpenuhi dan bertambahnya kepuasan konsumen.

2. PT. Telkomsel harus berusaha mewujudkan segala ekspektasi pelanggan dengan tujuan mempertahankan loyalitas pelanggan sehingga profitabilitas perusahaan juga semakin meningkat.

3. PT. Telkomsel juga harus meraih pangsa pasar yang lebih besar dengan produk-produk yang lebih inovativ sehingga dapat menciptakan loyalitas konsumen yang sustainable. 


\section{DAFTAR PUSTAKA}

Ferdinand, A.T., 2006 , Metode Penelitian Manajemen, BP Undip, Semarang.

Hatane Samuel dan Foedjiawati (2005) Pengaruh Kepuasan Konsumen Terhadap Kesetiaan Merek (Studi Kasus Restoran The Prime Steak \& Ribs Surabaya), Jurnal Manajemen \& Kewirausahaan, Vol. 7 No.1, Surabaya : Fakultas Ekonomi-Universitas Kristen Petra.

Julita (2001) "Menuju Kepuasan Pelanggan melalui Penciptaan kualitas pelayanan" Jurnal Ilmiah manajemen dan Bisnis, Vol. 01, No. 01 : 41-54.

Kotler, Philip (2007) Manajemen Pemasaran, Edisi Millenium, Jilid 2, PT. Indeks, Jakarta.

Malhotra, K, Naresh, (2006), Riset Pemasaran Pendekatan Terapan, PT. Indeks Kelompok Gramedia, Jakarta.

Pearce and Robinson (2005 Strategi Perusahaan, Erlangga, Jakarta.

Prahald (1995), CONSUMER BEHAVIOUR Perilaku Konsumen dan Strategi Pemasaran, Edisi 4, Jilid 1, Erlangga, Jakarta.

Rangkuti, Freddy (2003), Riset Pemasaran, PT.Gramedia Pustaka Utama, Jakarta.

Sri, Mulyani, 2003, "Dampak Kualitas Jasa Pelayanan Terhadap Perilaku Konsumen”. Jurnal Gemawisata Vol. II No. 1, 2003.

Tjiptono, Fandy (2005) Pemasaran Jasa, Bayumedia, Surabaya. 